\title{
A dinâmica da base de exportação e crescimento econômico: análise no município de Varginha-MG
}

\author{
Pedro dos Santos Portugal Júnior ${ }^{1}$ \\ Rodrigo Franklin Frogeri ${ }^{2}$ \\ Alessandro Ferreira Alves ${ }^{3}$ \\ Eduardo Gomes Carvalho ${ }^{4}$ \\ Fabrício Pelloso Piurcosky ${ }^{5}$
}

\begin{abstract}
Resumo
O desempenho das exportações e da pauta exportadora consistem em componentes importantes do crescimento econômico tanto a nível de países como em espaços territoriais. Destarte, o objetivo deste estudo é analisar a influência do comportamento das exportações no crescimento econômico do município de Varginha - MG. Metodologicamente o estudo se caracterizou como de abordagem quantitativa, realizado por meio de técnicas de estatística descritiva, correlação bivariada, regressão múltipla e teoria da decisão estatística. Os resultados evidenciaram uma relação baixa e não significativa das taxas de crescimento das exportações e do Produto Interno Bruto no município. A pauta de exportação se mostrou estática e dependente de uma commodity agrícola o que explica essa baixa relação. O crescimento do setor agropecuário também demonstrou baixa relação e não significativa com o crescimento econômico e com a variação dos demais setores. Salienta-se a necessidade de dinamizar a base exportadora e integrá-la para um melhor crescimento local.
\end{abstract}

Palavras-chave: Teoria da base de exportação; crescimento econômico; desenvolvimento regional.

\section{The Dynamics of the Export Base and Economic Growth: analysis in Varginha municipality - State of Minas Gerais}

\begin{abstract}
Export performance and export ruling consist of important components of economic growth both at country level and in territorial spaces. Therefore, study aim to analyze the influence of the export behavior on economic growth of Varginha - MG municipality. Methodologically, the study was characterized as a quantitative approach, carried out by means of descriptive statistics techniques, bivariate correlation, multiple regression and statistical decision theory. Results showed a low and non-significant relation of the growth rates of exports and Gross Domestic Product in the municipality. Export guideline proved to be static and dependent on an agricultural commodity which explains this low relation. Agricultural sector growth also showed low and non-significant relation with economic growth and with another sectors variation. This study results highlighted necessity to boost the export base and integrate it for better local growth.
\end{abstract}

Keywords: Export base theory; economic growth; regional development.

\footnotetext{
1 Pós-doutorado e doutorado em Desenvolvimento Econômico (UNICAMP). Professor no Programa de PósGraduação em Gestão e Desenvolvimento Regional do Centro Universitário do Sul de Minas Gerais (UNIS-MG). http://orcid.org/0000-0003-2590-1959 E-mail: pedro.junior@unis.edu.br

2 Doutorado em Sistemas de Informação e Gestão do Conhecimento (FUMEC). Professor do Programa de PósGraduação em Gestão e Desenvolvimento Regional do Centro Universitário do Sul de Minas Gerais (UNIS-MG). https://orcid.org/0000-0002-7545-7529 E-mail: rodrigo.frogeri@professor.unis.edu.br

${ }^{3}$ Doutorado em Matemática Aplicada a Engenharia Elétrica (UNICAMP). Professor do Programa de Pós-Graduação em Gestão e Desenvolvimento Regional do Centro Universitário do Sul de Minas Gerais (UNIS-MG). https://orcid.org/0000-0002-5266-375X E-mail: alessandro.alves@unis.edu.br

${ }^{4}$ Doutorado em Administração (UFLA). Professor do Centro Federal de Educação Tecnológica de Minas Gerais (CEFET-MG). https://orcid.org/0000-0002-5266-375X Email:eduardogomes@cefetmg.br
}

5 Doutorado em Administração (UFLA). Professor do Centro Universitário do Sul de Minas (UNIS-MG). https://orcid.org/0000-0001-5458-5129 E-mail:fabricio@unis.edu.br 


\section{Introdução}

Compreender a dinâmica da economia em determinado território é uma tarefa complexa e que exige estudos avançados e profundos a fim de identificar fatores que auxiliam no entendimento desse processo. Essa dinâmica emerge como base para o crescimento econômico regional, tendo como pressupostos as noções de Perroux (1977) e Schumpeter (1942) de que o crescimento é diferenciado em cada parte do território, manifestando-se em polos de crescimento com intensidade e efeitos finais bastante variáveis e tendo na inovação o efeito propulsor das novas combinações. Assim, compreende-se que cada território e mesmo cada polo de crescimento apresenta características intrínsecas que lhe tornam diferenciado e como tal demandam-se análises que permitam compreender, mesmo que minimamente, esse comportamento.

Dentre as dinâmicas econômicas, o desempenho das exportações e da própria pauta de produtos exportáveis aparece como um componente importante do crescimento econômico e da sua evolução em um determinado período, tanto a nível de países como em outros espaços territoriais (GALIMBERTI; CALDART, 2010).

Na visão de Lima e Simões (2009), como o processo de crescimento e desenvolvimento econômico não ocorrem de maneira igual e simultânea em todo o território, gera-se um processo irregular e com características de fortalecer certas áreas e regiões mais dinâmicas. No mesmo sentido está a afirmação de Hirschman (1958) de que o progresso do desenvolvimento econômico não ocorre simultaneamente em toda parte, mas se concentra espacialmente ao redor do ponto onde se inicia, geralmente o polo da região. Por isso, justifica-se um estudo sobre essa temática, visto que a análise apenas a nível nacional ou estadual não permite explicar o comportamento regional e local, portanto emerge a necessidade de avaliações municipais, especialmente das denominadas cidades polo.

A escolha do município de Varginha se deu exatamente em razão de sua importância no espaço regional, sendo uma cidade polo da região Sul de Minas, inclusive indicada como região intermediária segundo a nova classificação do IBGE (2017). Dentre os 155 municípios componentes do Sul de Minas Gerais, Varginha é a terceira maior em população com projeção de 134.477 habitantes em 2018. Analisando sob a ótica microrregional em que está inserido (Microrregião de Varginha) o município é o mais populoso e sua economia representa 43,23\% do PIB da Microrregião que é composta por 16 municípios (FJP, 2020). Partindo-se dessas questões, coloca-se o problema de pesquisa: qual a relação entre o comportamento das exportações e sua 
influência no crescimento econômico do município de Varginha - MG?

Destarte, o objetivo do estudo é analisar a relação entre o comportamento das exportações e sua influência no crescimento econômico do município de Varginha - MG. Metodologicamente o estudo se caracterizou como de abordagem quantitativa, realizado por meio de técnicas de estatística descritiva, correlação bivariada, regressão múltipla e teoria da decisão estatística

Estudos semelhantes já foram produzidos sobre essa temática, dentre os quais se destacam Crespo-Cuaresma, Wörz (2003), Galimberti e Caldart (2010) e Carmo, Raiher e Stege (2017). No entanto, os últimos dois estudos não levaram em consideração a composição da pauta de exportação local em suas análises, fato que a presente pesquisa busca apresentar.

O trabalho está dividido em cinco partes, incluindo essa introdução. Em seguida apresenta-se o referencial teórico abordando as principais teorias do desenvolvimento regional, com ênfase maior sobre a Teoria da Base de Exportação de Douglas North. Na terceira parte explica-se a metodologia aplicada no estudo e na quarta parte são apresentadas as análises e discussão dos dados levantados, primeiramente com a relação entre exportação e PIB e depois dos setores com o PIB. Por último, apresentam-se as considerações finais.

\section{Referencial teórico}

Nesse item abordam-se alguns referenciais sobre as principais teorias que explicam, ou procuram explicar, a questão do desenvolvimento regional, enfatizando de forma mais efetiva a Teoria da Base de Exportação de Douglas North.

\subsection{Teorias do desenvolvimento regional}

A inclusão da questão regional e espacial no âmbito dos estudos econômicos ocorreu apenas no século XIX. Von Thünen abordou o tema localização de atividades agrícolas; Weber discutiu os custos de transporte, localização industrial e economias de aglomeração; enquanto Christaller tratou sobre localizações centrais e a posição das atividades terciárias (BENKO, 1999). Mais tarde, no século XX, o surgimento da Ciência Regional (Regional Science) e da Comissão Econômica para América Latina e Caribe (Cepal) contribuíram para a evolução das chamadas teorias do desenvolvimento regional, das quais o presente estudo discute algumas. 
A Teoria dos Polos de Crescimento, desenvolvida por Perroux (1967) e Boudeville (1970), destaca a importância da indústria motriz, do complexo industrial e o crescimento dos polos de desenvolvimento. Dessa forma, a economia nacional reflete a combinação de conjuntos ativos (formados pelas indústrias motrizes, polos de indústrias e de atividades geograficamente concentrados) e passivos (com indústrias movidas e regiões dependentes dos polos geograficamente concentrados). Os conjuntos ativos induzem o crescimento dos conjuntos passivos.

Para Souza (2005), a indústria motriz apresenta algumas características: i) cresce acima da média nacional; ii) apresenta fortes ligações locais de insumo-produto; iii) apresenta uma atividade inovadora de grande dimensão e oligopolista; iv) possui grande poder de mercado, atraindo empresas satélites; v) sua produção se destina ao mercado interno e externo. Nota-se assim uma forte relação entre a Teoria dos Polos de Crescimento e a noção Schumpeteriana, visto que a indústria motriz deve ser inovadora e grande, e tem por direcionamento romper com o fluxo puramente circular da produção e promover as novas combinações e a destruição criadora no sentido de Schumpeter (1942) através, principalmente, da Pesquisa e Desenvolvimento (P\&D).

Assim, o polo se configura como um conjunto de atividades fortemente conectadas e lideradas pela indústria motriz gerando efeitos adicionais na economia (SOUZA, 2005). Para Lima e Simões (2009), o país encontraria nos polos de crescimento a sua força e o seu meio vital. Porém, cabe destacar que a indústria motriz e as indústrias induzidas necessitam de infraestruturas, mão de obra qualificada e serviços básicos para a população (saneamento, habitação, segurança e saúde) para fomentar o desenvolvimento regional.

Para Myrdal (1957), o desenvolvimento ocorre em um processo de causação circular cumulativa, ou seja, um sistema social interno se movimenta sob a influência de questões exógenas. Dessa forma, nos países subdesenvolvidos, as políticas são fundamentais para diminuir as disparidades regionais, intensificar os efeitos de propagação e minimizar os efeitos de retrocesso, estimulando assim o desenvolvimento em causação circular.

Outra importante contribuição sobre essa temática remete a Hirschman (1958) segundo o qual o desenvolvimento ocorre em cadeias de desequilíbrio durante um longo prazo. Tal teoria surge em contraposição à noção de Nurkse (1957) de que o desenvolvimento deve ser equilibrado e diversificado rompendo o círculo vicioso do subdesenvolvimento por meio da criação de várias atividades produtivas concomitantemente. Para Hirschman (1958), os projetos 
de investimento devem ser ranqueados conforme os seus retornos sociais e a sequência ideal de realização. Pois, a dispersão de recursos, para manter o crescimento equilibrado, enfraquece os efeitos de encadeamento no interior do polo, anulando a propagação espacial do crescimento entre as regiões. Nesse sentido o governo deve prover a infraestrutura social para impulsionar a atividade produtiva e elaborar uma estratégia de desenvolvimento com a determinação das áreas prioritárias.

\subsection{Exportação e crescimento econômico}

Para o presente estudo a teoria que será tomada como fundamento é a da Base de Exportação, desenvolvida por North (1955). Para este autor a base de exportação representa os produtos exportáveis de uma região. O desenvolvimento de um produto de exportação reflete uma vantagem comparativa nos custos relativos da produção, dentre eles os de transporte. À medida que a região cresce em torno desta base geram-se economias externas que estimulam a competitividade, sem a necessidade de apresentar inicialmente vantagens de localização.

Tanto o desenvolvimento de uma organização de comercialização especializada, como as melhorias nas áreas de crédito e de transporte, a especialização da mão de obra e as indústrias complementares (ou induzidas no sentido de Perroux) são influenciadas a partir da base de exportação (NORTH, 1955). Em obra posterior, North (1959) complementou que também a produção de bens agrícolas voltados para exportação, quando bem-sucedida e dinâmica, pode contribuir para o crescimento econômico de uma região.

No entanto, cabe salientar que essa base de exportação não deve ser estática, mas sim dinâmica, pois o país e a região crescerão por meio da diversificação e diferenciação dessa base. Isso é fundamentado em North (1955) ao afirmar que o principal produto de exportação tem um papel vital nas flutuações cíclicas da economia da região. As regiões que se especializam em poucos produtos e sem melhorias e evoluções nos mesmos, ou seja, apresentam uma base exportadora estática e contínua, tendem a apresentar flutuações mais abruptas do que as regiões com pauta mais diversificada e com inovações em seus bens e serviços transacionáveis.

Além disso, segundo o mesmo autor, a dinâmica da mão de obra será influenciada pelas bases de exportação no que tange às especializações requeridas, a estabilidade das ocupações e as condições de trabalho. Mesmo que a base seja fundamentada em atividades capitalintensivas, sua expansão e integração com as atividades complementares contribui para a 
absorção da mão de obra.

Nessa mesma linha têm-se a noção de Thirlwall (2000) ao afirmar que as relações comerciais com o exterior impactam o crescimento econômico através do aperfeiçoamento da eficiência e dos estímulos às exportações, que influenciam tanto a oferta como a demanda de uma economia. Cabe destacar também que as exportações podem incentivar o crescimento econômico através da promoção de economias de escala, utilização mais ampla da capacidade produtiva, ganhos de produtividade e melhor variedade de produtos; o que é possível ocorrer em regiões com base exportadora mais complexa e dinâmica (CRESPO-CUARESMA, WÖRZ, 2003; GALA, 2017). A base exportadora também pode contribuir para a ocorrência de externalidades positivas entre os diferentes setores da economia gerando ganhos dinâmicos (FEDER, 1983).

Nesse sentido, na medida em que a base de exportação proporciona ganhos, uma parte destes lucros é reinvestido na expansão e melhoria dessa base, tornando-a mais dinâmica e inovadora. Com isso, a atual estrutura de exportação e de produção para o mercado interno geram uma nova base de exportação e novos produtos para o mercado interno. Assim sendo, a exportação se torna a variável-chave do crescimento e a economia local criativa desenvolve novos produtos exportáveis. No entanto, quando o capital é direcionado a atividades que não são conectadas entre si, sua capacidade de criar novos bens e serviços é baixa e são criados blocos econômicos que se tornam enclaves.

A teoria de North sofreu críticas, dentre as quais destaca-se Tiebout (1977) cuja discordância se baseava no fato de que seria errôneo supor que a exportação poderia ser indicada como a variável única ou mais determinante no crescimento da renda regional, havendo outras atividades tão ou mais importantes que a exportação.

Mesmo sendo alvo de críticas, a teoria da base de exportação de North ainda permanece sendo estudada e aplicada para o entendimento do desenvolvimento regional, mesmo que visando demonstrar que ela não é tão efetiva na explicação da realidade analisada. Evidencia-se que a teoria preconizada por North critica a consideração do processo de desenvolvimento como etapas sequenciais, tanto em países já desenvolvidos como também nos países subdesenvolvidos e em desenvolvimento, como o Brasil. Isso fundamenta o fato de que tal processo não é etapista, mas se reveste de um contexto histórico e estrutural importante conforme defende Furtado (2000).

O trabalho de Lima et al. (2013) analisou a aplicação da teoria da base de exportação para o estado de Santa Catarina, demonstrando a importância do setor industrial exportador e a 
transição não tão dinâmica que estava ocorrendo para o setor de serviços sem o surgimento de novas atividades básicas de perfil exportador.

A cidade de Varginha, foco deste estudo, se apresenta como um locus de pesquisa interessante para observar a teoria da base de exportações de North por possuir uma Estação Aduaneira do Interior (EADI), conhecida como Porto Seco Sul de Minas, que serve como recinto alfandegado para os processos de exportação e importação da cidade e do seu entorno. Além disso, Varginha localiza-se no sul do estado de Minas Gerais que é a maior região produtora de café arábica do país e tendo em sua microrregião a presença dos dois maiores municípios produtores desta commodity: Campos Gerais e Três Pontas (EMATER, 2019).

Partindo-se desse arcabouço teórico e como resposta ao problema de pesquisa e ao objetivo elencado foram definidas duas hipóteses, a saber: HO - exportações de Varginha, sendo muito dependentes de commodities agrícolas, não contribuem de forma significativa para o crescimento econômico do município; e, H1 - o crescimento do setor agropecuário não tem relação significativa com o crescimento do PIB municipal no período analisado. Estas duas hipóteses foram testadas e os resultados foram apresentados na seção 4 deste artigo.

\section{Metodologia}

Para atender aos objetivos determinados para esse estudo optou-se por um estudo que se caracteriza metodologicamente como de abordagem quantitativa, epistemologia positivista e lógica hipotética-dedutiva.

Trata-se de um estudo de caso que, segundo Yin (2015), analisa um determinado fenômeno de maneira exaustiva e aprofundada a fim de conhecer uma realidade na qual os limites entre o fenômeno e o contexto não são claramente evidentes. Importante destacar que os resultados de um estudo de caso não podem ser generalizados, mas compreendem apenas a explicação da realidade local estudada, no caso, o município de Varginha em relação ao comportamento das exportações, do crescimento econômico em geral e dos setores econômicos em particular.

\subsection{Variáveis e fontes de dados}

Nesse item são especificados os tipos de dados utilizados e as fontes em que eles foram 
levantados. Cumpre salientar que como medida do crescimento econômico utilizou-se o Produto Interno Bruto (PIB), sendo esta a variável mais comum para mensuração da atividade econômica agregada, representando o total de bens e serviços finais produzidos dentro de um país, estado ou cidade em determinado período (ABEL; BERNANKE; CROUSHORE, 2008).

Os dados foram levantados em diferentes fontes como Fundação João Pinheiro (2020) de onde se extraíram os dados sobre o PIB total do município e o valor adicionado bruto de cada setor, a saber: agropecuária, indústria, serviços e setor público. Do IBGE (2019) se apurou o deflator oficial do PIB, tendo em vista que os dados levantados do PIB e do valor adicionado de cada setor estavam em preços correntes e, com isso, se faz necessário excluir a influência da variação de preços (Quadro 1).

No que se refere aos dados sobre as exportações do município, a fonte utilizada foi a divisão Indústria, Comércio Exterior e Serviços (antigo Ministério do Desenvolvimento, Indústria e Comércio Exterior - MDIC, 2020b) atualmente sob a égide do Ministério da Economia. Como esses dados de exportações são apresentados em dólares, foi necessário convertê-los para reais usando a taxa média de câmbio anual segundo IPEA (2020) e, também, os deflacionar com base no deflator oficial do IBGE (2019).

Quadro 1. Resumo dos dados, fontes, períodos e finalidade

\begin{tabular}{|c|c|c|c|}
\hline Dado & Fonte pesquisada & $\begin{array}{l}\text { Período } \\
\text { levantado }\end{array}$ & Finalidade \\
\hline PIB total do município. & $\begin{array}{l}\text { Fundação João Pinheiro } \\
(2020)\end{array}$ & 2003 a 2017 & $\begin{array}{l}\text { Determinar o crescimento econômico } \\
\text { anual do PIB. }\end{array}$ \\
\hline $\begin{array}{l}\text { Valor adicionado bruto } \\
\text { dos setores agropecuária, } \\
\text { indústria, serviços e setor } \\
\text { público no município. }\end{array}$ & $\begin{array}{l}\text { Fundação João Pinheiro } \\
\text { (2020) }\end{array}$ & 2003 a 2017 & $\begin{array}{l}\text { Determinar o crescimento econômico } \\
\text { de cada setor. }\end{array}$ \\
\hline Deflator oficial do PIB. & IBGE (2019) & 2003 a 2017 & $\begin{array}{l}\text { Deflacionar as séries de dados que } \\
\text { estão valores correntes, isolando o } \\
\text { fator variação dos preços dos dados. }\end{array}$ \\
\hline $\begin{array}{l}\text { Valor anual das } \\
\text { exportações do município. }\end{array}$ & $\begin{array}{l}\text { Divisão Indústria, } \\
\text { Comércio Exterior e } \\
\text { Serviços (MDIC, 2020b) } \\
\text { do Ministério da } \\
\text { Economia. }\end{array}$ & 2003 a 2017 & $\begin{array}{l}\text { Determinar o crescimento das } \\
\text { exportações a cada ano. }\end{array}$ \\
\hline $\begin{array}{l}\text { Taxa média anual do } \\
\text { câmbio (US\$ - R\$). }\end{array}$ & IPEA (2020) & 2003 a 2017 & $\begin{array}{l}\text { Converter os valores de exportação de } \\
\text { US\$ para R\$. }\end{array}$ \\
\hline $\begin{array}{l}\text { Pauta exportadora do } \\
\text { município. }\end{array}$ & MDIC (2020a) & 2009 a 2017 & $\begin{array}{l}\text { Compreender o comportamento da } \\
\text { pauta de exportação no período, } \\
\text { verificando os produtos mais } \\
\text { comercializados. }\end{array}$ \\
\hline
\end{tabular}

Fonte: elaborado pelos autores. 
Os dados informados anteriormente abrangeram o período de 2003 a 2017 que corresponde à totalidade das informações disponíveis nas fontes pesquisadas. Os dados sobre PIB total e por setores são divulgados com dois anos de defasagem, dessa forma, quando do desenvolvimento deste estudo, o último ano com essas informações disponíveis era de 2017.

Também do MDIC (2020a) se extraiu os dados sobre a pauta de exportação do município pesquisado seguindo a nomenclatura ISIC - Classificação Internacional de Todas as Atividades Econômicas. Porém, cabe salientar que esses dados abrangeram apenas o período de 2009 a 2017, visto que anterior a esse prazo não havia informações disponíveis. O próximo item explica os métodos e testes estatísticos aplicados no estudo. Destaca-se que as análises foram realizadas por meio do software SPSS versão 24.0.

\subsection{Métodos e testes empregados na pesquisa}

Os testes de normalidade Kolmogorov-Smirnov (K-S) e Shapiro-Wilk (S-W), demonstrados no item 3.2.1, foram usados para definir o método de correlação mais apropriado para os dados em análise (TORMAN; COSTER; RIBOLDI, 2012). Mesmo os testes indicando normalidade na série de dados optou-se pelo uso do coeficiente de correlação de Spearman, visto que o número de observações e dados foi abaixo de 30 (BISQUERA, SARIERRA, MARTINEZ, 2004; ÖZTUNA; ELHAN; TÜCCAR, 2006), pelo fato de serem esses os dados disponíveis nas fontes pesquisadas.

Feitas as devidas conversões procedeu-se a aplicação das análises estatísticas descritivas e do coeficiente de correlação de Spearman entre as taxas de crescimento das exportações e do PIB municipais no período de 2003 a 2017 (este foi o último ano de dados do PIB municipal) a fim de verificar a relação existente entre essas variáveis. Também se realizou essas análises estatísticas entre as taxas de crescimento do PIB e os setores econômicos municipais (Quadro 2).

Quadro 2. Parâmetros para análise do coeficiente de Spearman.

\begin{tabular}{|l|c|}
\hline Resultados & Spearman coeficiente \\
\hline$[0,90 ; 1]$ & Muito forte \\
\hline$[0,70 ; 0,89]$ & Forte \\
\hline$[0,40 ; 0,699]$ & Moderada \\
\hline$[0,20 ; 0,399]$ & Fraca \\
\hline$[0$ a 0,199$]$ & Muito fraca \\
\hline
\end{tabular}

Fonte: Finney (1980). 
Segundo Field (2009), os coeficientes de correlação são técnicas estatísticas que permitem mensurar a força de associação entre as variáveis em estudo e o que elas representam. Os principais coeficientes para descrição da associação entre variáveis são o Coeficiente de Correlação de Pearson e o Coeficiente de Spearman, ambos variando entre -1 e 1. Os resultados apresentados no quadro 2 da correlação foram analisados conforme Finney (1980). Nas seções seguintes são apresentadas as aplicações dos testes de normalidade e de homocedasticidade.

3.2.1 Teste de normalidade do crescimento das exportações e do crescimento do PIB

De acordo com a teoria da decisão estatística o teste de normalidade envolve um teste de hipótese, onde as hipóteses estatísticas são dadas por: HO: Os dados seguem uma distribuição normal de Gauss; e, H1: Os dados não seguem uma distribuição normal de Gauss.

O valor da probabilidade a priori estabelecida para as análises foi $\alpha=5 \%$. Deve ficar claro que, segundo Figueiredo Filho e Silva Júnior (2010), o resultado é um gráfico de probabilidade normal, com algumas estatísticas. De uma forma geral, cada ponto do gráfico é formado por um valor medido (no eixo horizontal) e a probabilidade acumulada (no eixo vertical). A ideia fundamental do método é que uma transformação é aplicada no eixo vertical do gráfico da distribuição acumulada. Assim, se a distribuição dos dados for normal, esta transformação torna a distribuição acumulada uma reta. Se for muito diferente da reta, provavelmente os dados não seguem uma distribuição normal (Gráfico 1).

Gráfico 1. Teste de normalidade para o crescimento das exportações em Varginha de 2003 a 2017

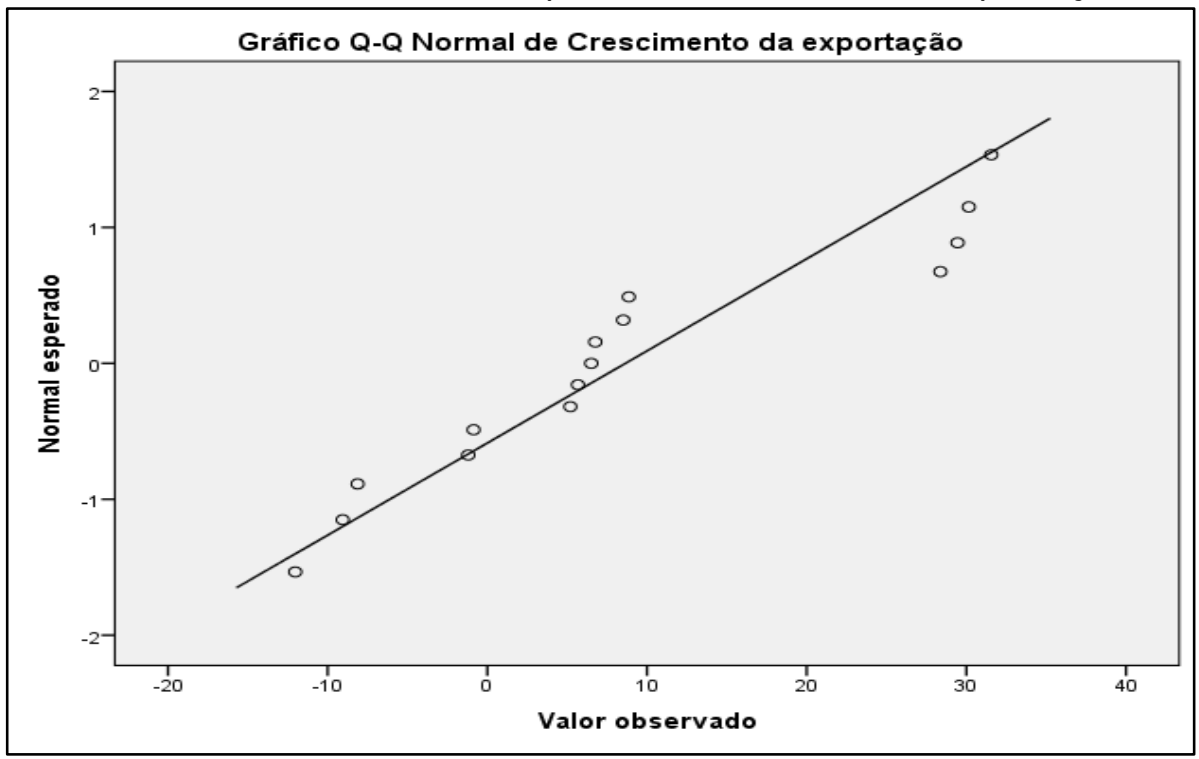

Fonte: elaborado pelos autores. 
Quanto mais próximos da reta estiverem os pontos, maior a chance de a variável seguir uma distribuição normal. O Gráfico 1 destaca o teste de normalidade para o crescimento das exportações na cidade de Varginha entre os anos de 2003 e 2017. Na Tabela 1 é apresentada a análise do teste de normalidade para o crescimento das exportações da cidade de Varginha.

Tabela 1. Análise do teste de normalidade para o crescimento das exportações

\begin{tabular}{l|ccc|ccc}
\hline \multicolumn{7}{|c|}{ Teste de Normalidade } \\
\hline & Kolmogorov-Smirnov ${ }^{\mathrm{a}}$ & & \multicolumn{3}{l}{ Shapiro-Wilk } & \\
\hline \multirow{2}{*}{$\begin{array}{l}\text { Crescimento } \\
\text { das exportações }\end{array}$} & Estatística & $\begin{array}{l}\text { Graus de } \\
\text { liberdade }\end{array}$ & p-valor & Estatística & $\begin{array}{l}\text { Graus de } \\
\text { liberdade }\end{array}$ & p-valor \\
\cline { 2 - 7 } & 0,228 & 15 & 0,065 & 0,887 & 15 & 0,060 \\
\hline
\end{tabular}

Fonte: elaborado pelos autores.

a. Lilliefors Significance Correction

Desta forma, independentemente do teste de normalidade realizado, KolmogorovSmirnov ou Shapiro-Wilk, a variável "Crescimento das Exportações" apresenta normalidade (pois, em ambos os casos p-valor > 5\%). Especificamente, percebe-se que para o teste de KolmogorovSmirnov o p-valor é igual a 6,5\%, enquanto para o teste de Shapiro-Wilk o p-valor é a igual 6\%.

Gráfico 2. Teste de normalidade para o crescimento do PIB em Varginha de 2003 a 2017.

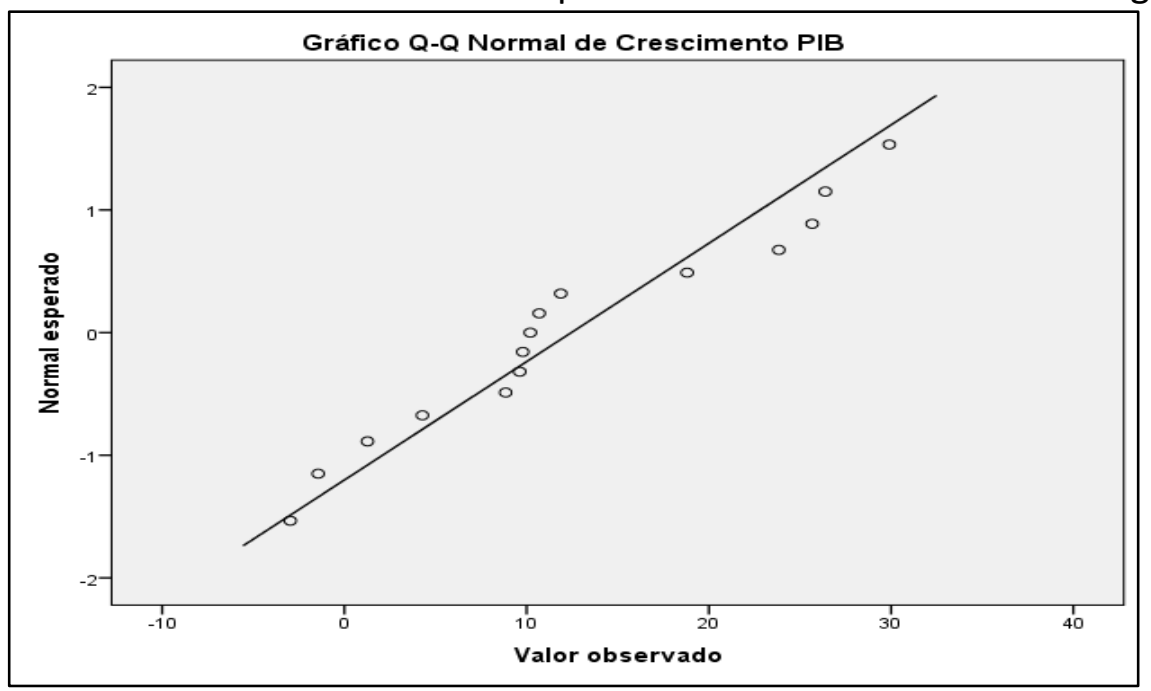

Fonte: elaborado pelos autores.

A seguir, na tabela 2, são apresentados os resultados da análise do teste de normalidade para o crescimento do PIB do município de Varginha-MG.

Tabela 2. Análise do teste de normalidade para o crescimento do PIB.

\begin{tabular}{|c|c|c|c|c|c|c|}
\hline \multirow[b]{4}{*}{ Crescimento do PIB: } & \multicolumn{6}{|c|}{$\begin{array}{ll}\text { Teste de Normalidade } \\
\end{array}$} \\
\hline & \multicolumn{3}{|c|}{ Kolmogorov-Smirnov ${ }^{\mathrm{a}}$} & \multicolumn{3}{|c|}{ Shapiro-Wilk } \\
\hline & Estatística & $\begin{array}{l}\text { Graus de } \\
\text { liberdade }\end{array}$ & p-valor & Estatística & $\begin{array}{l}\text { Graus de } \\
\text { liberdade }\end{array}$ & p-valor \\
\hline & 0,189 & 15 & 0,155 & 0,934 & 15 & 0,317 \\
\hline
\end{tabular}


Mais uma vez, independentemente do teste de normalidade realizado, KolmogorovSmirnov ou Shapiro-Wilk, para a variável "Crescimento do PIB" os dados apresentam normalidade (pois, em ambos os casos $p$-valor $>5 \%$ ). Especificamente, para o teste de Kolmogorov-Smirnov o p-valor igual a 15,5\%, enquanto para o teste de Shapiro-Wilk o p-valor igual a $31,7 \%$.

3.2.2 Teste de homocedasticidade entre crescimento das exportações e crescimento do PIB

Segundo Bisquera, Sarierra e Martinez (2004) duas ou mais distribuições de valores apresentam homocedasticidade quando as respectivas variações são equivalentes em linhas estatísticas. Ou seja, diversas distribuições de valores possuem homocedasticidade ou homogeneidade de variâncias quando as diferenças notadas entre as variâncias não são estatisticamente significativas. Contrariamente, quando tal fato não acontece, afirma-se que ocorre heteroscedasticidade.

Para analisar a homoscedasticidade entre o "Crescimento das Exportações" e o "Crescimento do PIB" usou-se o método da "Comparação de duas Variâncias com Dados Emparelhados", que segundo Bisquera, Sarierra e Martinez (2004) tem como expressão característica:

$$
Z=\frac{S_{1}^{2}-S_{2}^{2}}{\sqrt{\frac{4 \cdot S_{1}^{2} \cdot S_{2}^{2}\left(1-r^{2}\right)}{n-2}}}
$$

Onde:

$\mathrm{n}$ : número de casos de cada grupo

$S_{1}^{2}::$ variância do grupo 1

$S_{2}^{2}::$ variância do grupo 2

r: coeficiente de correlação

No caso deste estudo, considerando o grupo 2 (Crescimento das Exportaçõeso) e Grupo 1 (Crescimento do PIB), tem-se a seguinte expressão:

$$
Z=\frac{107,340-14,75508}{\sqrt{\frac{4 .)(107,340) \cdot(14,75508)\left(1-0,291^{2}\right)}{15-2}}}
$$




$$
Z=107,146235704163
$$

Desta forma, é possível afirmar que com Z = 107,146235704163 > 2,576 (valor da tabela da normal para $\alpha=5 \%$ ) rejeita-se a hipótese nula ao nível $\alpha=5 \%$, ou seja, conclui-se que as variâncias do "Crescimento do PIB" e do "Crescimento das Exportações" apresentam diferenças significativas, ou seja, são distribuições que apresentam heteroscedasticidade.

\subsubsection{Teste de homocedasticidade dos resíduos}

Outra suposição apresentada por Hair Jr. et al (2009) em análise de regressão múltipla é a variância constante do termo de erro. De acordo com Hair Jr. et al (2009) a presença de variâncias desiguais (heterocedasticidade) é uma das violações mais comuns de suposição. Para identificar tal violação, os autores sugerem avaliar a representação gráfica dos resíduos versus as variáveis independentes ou previstas (Gráfico 3 e Gráfico 4).

Gráfico 3. Teste de homocedasticidade dos resíduos studentizado.

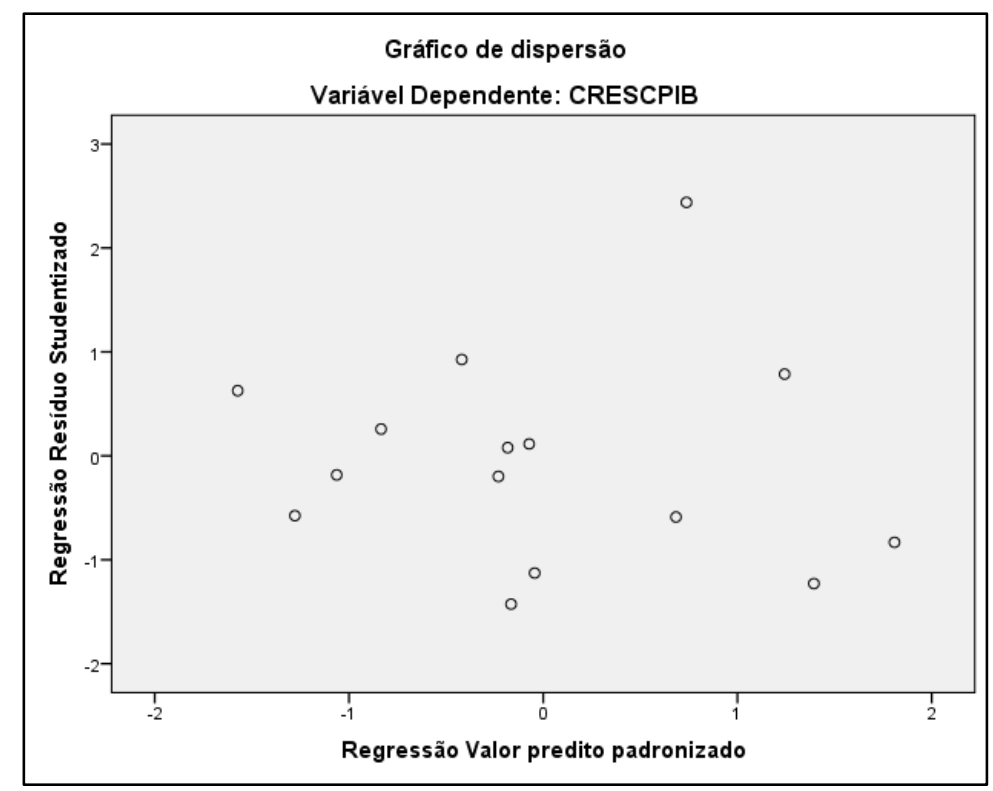

Fonte: elaborado pelos autores. 
Gráfico 4. Teste de homocedasticidade dos resíduos padronizados.

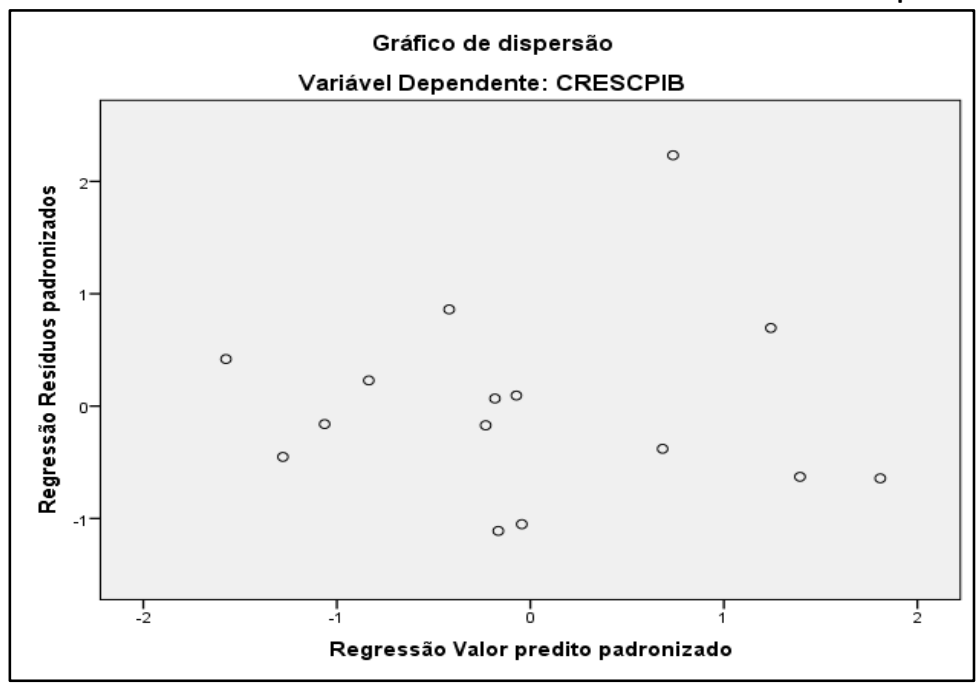

Fonte: elaborado pelos autores.

A partir da observação dos gráficos 3 e 4 foi possível afirmar que os resíduos ocorrem aleatoriamente, não apresentando nenhum padrão, o que permite descartar a presença de variâncias desiguais. A seguir demonstram-se as implicações destes resultados estatísticosmetodológicos para o resultado do estudo da relação do "Crescimento do PIB" com o "Crescimento das Exportações".

\section{Análise e discussão}

Nesse item são apresentados, analisados e discutidos, primeiramente, a relação entre as exportações e o PIB municipal, bem como o comportamento da pauta de exportação de Varginha no período de 2003 a 2017. Posteriormente, são apresentados os dados referentes ao comportamento da variação dos setores econômicos e sua relação com o PIB e exportação.

\subsection{Análise das exportações e do PIB}

Primeiramente, são apresentadas as estatísticas descritivas, tais como medidas de centralidade e dispersão, bem como os coeficientes de assimetria e curtose das taxas anuais de crescimento das exportações e do PIB municipal, conforme Figura 1.

Cabe destacar nessas estatísticas descritivas o maior desvio padrão das taxas de crescimento das exportações em Varginha, fato que demonstra que essa variável é mais volátil em relação à sua média do que a taxa de crescimento do PIB, ou seja, os seus valores sofrem 
maiores variações para com a exportação média alcançada no período (8,6507\%). Em termos econômicos representa que a variável crescimento das exportações é muito inconstante neste município o que pode impactar suas influências no crescimento econômico ou que os valores dos produtos mais exportados sejam muito inconstantes, o que é típico do comportamento de commodities.

Para analisar o grau de relacionamento entre as variáveis Crescimento das Exportações(X) e Crescimento do PIB (Y) utiliza-se o valor do coeficiente de correlação de Spearman, interpretando o teste de hipóteses associado à correlação bivariada.

Para tal, o teste de hipóteses associado tem como hipóteses estatísticas: hipótese nula $(r=0)$, ou seja, o coeficiente de correlação $r$ obtido não é significativo; hipótese alternativa - ( $r \neq$ 0), ou seja, o coeficiente de correlação r obtido é significativo.

Figura 1. Análise descritiva do crescimento das exportações e do crescimento do PIB (2003-2017)

\begin{tabular}{|c|c|c|c|c|}
\hline & & & Estatística & $\begin{array}{l}\text { Modelo } \\
\text { padrão }\end{array}$ \\
\hline \multirow{13}{*}{$\begin{array}{l}\text { Crescimento da } \\
\text { exportação }\end{array}$} & Média & & 8,6507 & 3,80974 \\
\hline & \multirow{2}{*}{$\begin{array}{l}\text { Intervalo de confiança de } \\
95 \% \text { para média }\end{array}$} & Limite inferior &, 4796 & \\
\hline & & Limite superior & 16,8218 & \\
\hline & \multicolumn{2}{|l|}{$5 \%$ da média aparada } & 8,5269 & \\
\hline & \multicolumn{2}{|l|}{ Mediana } & 6,5100 & \\
\hline & \multicolumn{2}{|l|}{ Variância } & 217,712 & \\
\hline & \multicolumn{2}{|l|}{ Desvio padrão } & 14,75508 & \\
\hline & \multicolumn{2}{|l|}{ Mínimo } & $-12,03$ & \\
\hline & \multicolumn{2}{|l|}{ Máximo } & 31,56 & \\
\hline & \multicolumn{2}{|l|}{ Range } & 43,59 & \\
\hline & \multicolumn{2}{|l|}{ Amplitude interquartil } & 29,57 & \\
\hline & \multicolumn{2}{|l|}{ Assimetria } &, 452 &, 580 \\
\hline & \multicolumn{2}{|l|}{ Kurtosis } &,- 973 & 1,121 \\
\hline \multirow[t]{13}{*}{ Crescimento PIB } & \multicolumn{2}{|l|}{ Média } & 12,4513 & 2,67508 \\
\hline & \multirow{2}{*}{$\begin{array}{l}\text { Intervalo de confiança de } \\
95 \% \text { para média }\end{array}$} & Limite inferior & 6,7139 & \\
\hline & & Limite superior & 18,1888 & \\
\hline & \multicolumn{2}{|l|}{$5 \%$ da média aparada } & 12,3387 & \\
\hline & \multicolumn{2}{|l|}{ Mediana } & 10,2000 & \\
\hline & \multicolumn{2}{|l|}{ Variância } & 107,340 & \\
\hline & \multicolumn{2}{|l|}{ Desvio padrão } & 10,36053 & \\
\hline & \multicolumn{2}{|l|}{ Mínimo } & $-2,97$ & \\
\hline & \multicolumn{2}{|l|}{ Máximo } & 29,90 & \\
\hline & \multicolumn{2}{|l|}{ Range } & 32,87 & \\
\hline & \multicolumn{2}{|l|}{ Amplitude interquartil } & 19,56 & \\
\hline & \multicolumn{2}{|l|}{ Assimetria } &, 272 &, 580 \\
\hline & \multicolumn{2}{|l|}{ Kurtosis } &,- 969 & 1,121 \\
\hline
\end{tabular}

Fonte: elaborada pelos autores.

Os dados sobre a dinâmica de crescimento das exportações e do Produto Interno Bruto 
do município de Varginha entre 2003 e 2017 são apresentados no quadro 3, a seguir.

Quadro 3. Taxas de crescimento das exportações e PIB municipal

\begin{tabular}{|l|r|r|}
\hline Ano & Crescimento das exportações & Crescimento do PIB \\
\hline $\mathbf{2 0 0 3}$ & $5,20 \%$ & $8,85 \%$ \\
\hline $\mathbf{2 0 0 4}$ & $31,56 \%$ & $25,67 \%$ \\
\hline $\mathbf{2 0 0 5}$ & $29,45 \%$ & $23,84 \%$ \\
\hline $\mathbf{2 0 0 6}$ & $-0,86 \%$ & $9,62 \%$ \\
\hline $\mathbf{2 0 0 7}$ & $6,76 \%$ & $29,90 \%$ \\
\hline $\mathbf{2 0 0 8}$ & $8,86 \%$ & $-1,44 \%$ \\
\hline $\mathbf{2 0 0 9}$ & $5,67 \%$ & $10,20 \%$ \\
\hline $\mathbf{2 0 1 0}$ & $8,51 \%$ & $18,81 \%$ \\
\hline $\mathbf{2 0 1 1}$ & $30,15 \%$ & $9,79 \%$ \\
\hline $\mathbf{2 0 1 2}$ & $-12,03 \%$ & $4,28 \%$ \\
\hline $\mathbf{2 0 1 3}$ & $-9,06 \%$ & $10,69 \%$ \\
\hline $\mathbf{2 0 1 4}$ & $28,37 \%$ & $11,87 \%$ \\
\hline $\mathbf{2 0 1 5}$ & $6,51 \%$ & $1,27 \%$ \\
\hline $\mathbf{2 0 1 6}$ & $-1,20 \%$ & $-2,97 \%$ \\
\hline $\mathbf{2 0 1 7}$ & $-8,13 \%$ & $26,39 \%$ \\
\hline
\end{tabular}

Fonte: elaborado pelos autores com base em MDIC (2020b) e FJP (2020).

A figura 2 apresenta a matriz de correlação entre a taxa de crescimento das exportações e o crescimento do PIB municipal no período considerado tendo como referência a probabilidade a priori $\alpha=5 \%$.

Figura 2. Matriz de correlação do Crescimento das Exportações e do Crescimento do PIB.

\begin{tabular}{|c|c|c|c|c|}
\hline & & & CrescExport & CrescPIB \\
\hline \multirow[t]{6}{*}{ Spearman's rho } & \multirow[t]{3}{*}{ CrescExport } & Correlation Coefficient & 1,000 & ,300 \\
\hline & & Sig. (2-tailed) & & 277 \\
\hline & & $\mathrm{N}$ & 15 & 15 \\
\hline & \multirow[t]{3}{*}{ CrescPIB } & Correlation Coefficient & 300 & 1,000 \\
\hline & & Sig. (2-tailed) & 277 & \\
\hline & & $\mathrm{N}$ & 15 & 15 \\
\hline
\end{tabular}

Fonte: elaborada pelos autores.

Analisando a Figura 2 é perceptível que não há correlação significativa entre o crescimento das exportações e do Produto Interno Bruto em Varginha no período de 2003 a 2017, já que o p-valor $=0,277$ ou $27,7 \%$ é maior do que $\alpha=5 \%$ e, por conseguinte aceita-se a hipótese nula (HO), ou seja, o coeficiente de correlação r obtido não é significativo, ou ainda, que a correlação entre as variáveis analisadas não é estatisticamente significativa. Tal fato reforça uma hipótese de que a base de exportação do município não possui uma relação direta e 
significativa com o crescimento econômico no período analisado. Importante salientar que a correlação demonstra apenas a relação entre as duas variáveis quantitativas analisadas (FIGUEIREDO FILHO; SILVA JUNIOR, 2010), não caracterizando uma associação de causa e efeito entre elas.

No entanto, mesmo com essa limitação da medida estatística, é possível considerar que a dinâmica das exportações não apresenta uma forte relação com a dinâmica da produção interna no município analisado, mesmo com a balança comercial sendo bastante superavitária segundo MDIC (2020a). Para aprofundar um pouco mais o estudo apresenta-se a pauta de exportação de Varginha por atividade econômica no período de 2009 a 2017, conforme a

Tabela 2. Foi adotado esse período em função dos dados disponíveis de forma desagregada para a análise, cujo início se dá em 2009.

Tabela 2. Pauta de exportação de Varginha por atividade econômica (em \%).

\begin{tabular}{|c|c|c|c|c|c|c|c|c|c|}
\hline $\begin{array}{l}\text { Atividade } \\
\text { econômica }\end{array}$ & 2009 & 2010 & 2011 & 2012 & 2013 & 2014 & 2015 & 2016 & 2017 \\
\hline Agropecuária & 95,7 & 97,2 & 97,9 & 97,1 & 97,3 & 97,5 & 97,6 & 95,3 & 94,8 \\
\hline $\begin{array}{l}\text { Indústria de } \\
\text { transformação }\end{array}$ & 4,28 & 2,8 & 2,084 & 2,89 & 2,73 & 2,5 & 2,35 & 2,13 & 3,3 \\
\hline $\begin{array}{l}\text { Indústria } \\
\text { extrativa }\end{array}$ & 0 & 0 & 0,026 & 0 & 0 & 0 & 0 & 2,56 & 1,93 \\
\hline $\begin{array}{l}\text { Outros } \\
\text { produtos }\end{array}$ & 0,02 & 0 & 0,0012 & 0,0003 & 0,0004 & 0 & 0,0004 & 0,000002 & \\
\hline
\end{tabular}

Fonte: MDIC (2020a).

Examinando esses dados é possível observar a pouca dinâmica da pauta exportadora de Varginha nesse período, visto que a atividade com maior participação sempre foi a agropecuária. Em média essa atividade representou 96,71\% do total exportado nesse período de 2009 a 2017. O fato de o principal produto de exportação ser o café arábica, principalmente em grão cru segundo MDIC (2020b), faz com que a base de exportação de Varginha seja dependente de uma commodity cujas cotações sofrem grandes volatilidades. Isso permite compreender a razão pela qual o desvio padrão da taxa de crescimento das exportações no município ser maior que das taxas de crescimento do PIB, conforme demonstrado na figura 1.

Essa realidade reforça o entendimento de que a base de exportação do município é muito estática e tende a não contribuir para o surgimento de novas bases de exportação e para o próprio dinamismo do crescimento no sentido preconizado por North (1955). Os resultados se aproximam, em certo sentido, da crítica de Tiebout (1977) de que somente a exportação pode não explicar o crescimento econômico local. Análise semelhante pode ser realizada com base em 
Gala (2017) de que a especialização em bens primários menos complexos não contribui para o desempenho econômico.

\subsection{Análise dos setores econômicos}

Tendo por base que a agropecuária é o principal setor exportador de Varginha e para analisar sua influência na dinâmica do crescimento do PIB, fez-se uma abordagem do crescimento de cada um dos setores econômicos e sua relação com o crescimento econômico no município no mesmo período de 2003 a 2017. A tabela 4 demonstra a taxa de crescimento anual de cada um dos setores econômicos: agropecuária, indústria, serviços, administração pública.

Tabela 3. Taxa de crescimento real anual dos setores econômicos em Varginha (\%).

\begin{tabular}{rrrrr}
\hline Ano & Agropecuária & Indústria & \multicolumn{1}{c}{ Serviços } & \multicolumn{2}{c}{ Administração Pública } \\
\hline 2003 & $-33,90 \%$ & $11,52 \%$ & $12,14 \%$ & $4,17 \%$ \\
2004 & $107,25 \%$ & $51,32 \%$ & $15,69 \%$ & $15,31 \%$ \\
2005 & $-18,60 \%$ & $21,21 \%$ & $20,65 \%$ & $11,27 \%$ \\
2006 & $54,16 \%$ & $5,11 \%$ & $8,45 \%$ & $11,88 \%$ \\
2007 & $-34,86 \%$ & $34,59 \%$ & $32,11 \%$ & $9,35 \%$ \\
2008 & $43,83 \%$ & $-1,68 \%$ & $-2,62 \%$ & $16,60 \%$ \\
2009 & $-10,12 \%$ & $4,17 \%$ & $15,42 \%$ & $12,61 \%$ \\
2010 & $19,05 \%$ & $-5,73 \%$ & $30,57 \%$ & $12,07 \%$ \\
2011 & $78,28 \%$ & $6,74 \%$ & $9,86 \%$ & $14,89 \%$ \\
2012 & $-25,71 \%$ & $1,56 \%$ & $4,85 \%$ & $10,42 \%$ \\
2013 & $-16,84 \%$ & $15,63 \%$ & $8,39 \%$ & $13,33 \%$ \\
2014 & $38,01 \%$ & $9,10 \%$ & $13,30 \%$ & $6,17 \%$ \\
2015 & $-16,62 \%$ & $-6,86 \%$ & $4,49 \%$ & $12,00 \%$ \\
2016 & $76,22 \%$ & $6,79 \%$ & $-9,57 \%$ & $6,66 \%$ \\
2017 & $1,31 \%$ & $17,20 \%$ & $29,85 \%$ & $11,58 \%$ \\
\hline
\end{tabular}

Fonte: elaborada pelos autores com base em FJP (2020).

As estatísticas descritivas desse conjunto de dados podem ser visualizadas na Figura 3, a seguir. São apresentadas na figura 3 as medidas de centralidade, de dispersão absoluta e relativa, bem como os coeficientes de assimetria e curtose.

Foi possível observar que o setor agropecuário apresenta a maior dispersão absoluta (maior desvio padrão) e maior dispersão relativa (maior erro padrão da média) em comparação com os demais setores, demonstrando uma alta volatilidade em suas taxas de crescimento em relação à sua média, ou seja, apresentando mais valores diferentes do que o seu valor médio. 0 menor desvio padrão refere-se ao setor da administração pública, o que significa que o seu nível de crescimento segue um padrão menos volátil de variação em relação à média, ou ainda, 
apresenta uma menor variação com base na sua média no período considerado para o estudo.

Figura 3. Estatísticas descritivas.

\begin{tabular}{||l|r|r|r|r|r|}
\hline \multicolumn{1}{|c|}{ Válido } & \multicolumn{1}{c|}{$\begin{array}{c}\text { Crescimento } \\
\text { Agropecuária }\end{array}$} & $\begin{array}{c}\text { Crescimento } \\
\text { Indústria }\end{array}$ & $\begin{array}{c}\text { Crescimento } \\
\text { Serviços }\end{array}$ & $\begin{array}{c}\text { Crescimento } \\
\text { Administração Pública }\end{array}$ \\
\hline Média & 15 & 15 & 15 & 15 \\
Erro de média padrão & 0 & 0 & 0 \\
Mediana & 17,4307 & 11,3780 & 12,9053 & 11,2207 \\
Moda & 11,86828 & 3,97254 & 3,06608 &, 89325 \\
Modelo padrão & 1,3100 & 6,7900 & 12,1400 & 11,8800 \\
Variância & $-34,86^{\text {a }}$ & $-6,86^{\text {a }}$ & $-9,57^{\text {a }}$ & $4,17^{\text {a }}$ \\
Assimetria & 45,96564 & 15,38559 & 11,87487 & 3,45956 \\
Erro de assimetria padrão & 2112,840 & 236,716 & 141,013 & 11,969 \\
Kurtosis &, 611 & 1,412 &, 076 &,- 586 \\
Erro de Curtose padrão &, 580 &, 580 &, 580 &, 580 \\
Amplitude &,- 910 & 2,283 &,- 216 &,- 018 \\
Mínimo & 1,121 & 1,121 & 1,121 & 1,121 \\
Máximo & 142,11 & 58,18 & 41,68 & 12,43 \\
\hline \multicolumn{2}{|c|}{ a. Há várias modas. O menor valor é mostrado } & $-6,86$ & $-9,57$ & 4,17 \\
\hline
\end{tabular}

Fonte: elaborada pelos autores.

Essa maior volatilidade do crescimento do setor agropecuário ajuda a explicar a maior volatilidade das exportações, visto ser este o setor responsável pela quase totalidade das exportações do município de Varginha. Na Figura 4, abaixo, apresenta a matriz de correlação entre as taxas de crescimento dos setores econômicos, o crescimento do PIB municipal e das exportações no período analisado.

A análise da figura 4 demonstra que o crescimento da agropecuária possui baixa relação negativa e não significativa para com o crescimento do PIB municipal. Soma-se o fato de que o crescimento das exportações também não apresenta relação significativa com nenhum dos setores econômicos. Tais percepções contribuem para reforçar a hipótese e explicar o motivo pelo qual a variação das exportações não possui relação com o crescimento econômico de Varginha, conforme já discutido anteriormente. Cabe ainda salientar que a variação do setor agropecuário não apresenta relação significativa com nenhum outro setor econômico, o que permite levantar uma hipótese de que ele não impacta de maneira direta o restante da economia municipal. Dessa forma evidencia-se mais uma vez que a base exportadora de Varginha, por ser estática e dependente de um setor pouco dinâmico, não contribui com o crescimento do município (Figura 4, a seguir). 
Figura 4. Matriz de correlação.

\begin{tabular}{|c|c|c|c|c|c|c|c|c|}
\hline & & & CrescExport & CrescPIB & CrescAgro & Cresclnd & CrescServ & $\begin{array}{l}\text { CrescAdm } \\
\text { Pub }\end{array}$ \\
\hline \multirow[t]{18}{*}{ Spearman's rho } & \multirow[t]{3}{*}{ CrescExport } & Correlation Coefficient & 1,000 & ,300 & ,396 & ,164 & ,332 & ,329 \\
\hline & & Sig. (2-tailed) & & ,277 & ,143 &, 558 & ,226 & 232 \\
\hline & & $\mathrm{N}$ & 15 & 15 & 15 & 15 & 15 & 15 \\
\hline & \multirow[t]{3}{*}{ CrescPIB } & Correlation Coefficient & ,300 & 1,000 & -161 & $671^{* *}$ & $921^{* *}$ & 007 \\
\hline & & Sig. (2-tailed) & ,277 & &, 567 & ,006 &, 000 & ,980 \\
\hline & & $\mathrm{N}$ & 15 & 15 & 15 & 15 & 15 & 15 \\
\hline & \multirow[t]{3}{*}{ CrescAgro } & Correlation Coefficient & ,396 &,- 161 & 1,000 &,- 107 &,- 236 & , 479 \\
\hline & & Sig. (2-tailed) & , 143 & ,567 & &, 704 & ,398 &, 071 \\
\hline & & $\mathrm{N}$ & 15 & 15 & 15 & 15 & 15 & 15 \\
\hline & \multirow[t]{3}{*}{ Cresclnd } & Correlation Coefficient & , 164 & ,671** &,- 107 & 1,000 & ,496 &,- 214 \\
\hline & & Sig. (2-tailed) &, 558 &, 006 &, 704 & . & ,060 & ,443 \\
\hline & & $\mathrm{N}$ & 15 & 15 & 15 & 15 & 15 & 15 \\
\hline & \multirow[t]{3}{*}{ CrescServ } & Correlation Coefficient & 332 & ,921** &,- 236 & 496 & 1,000 &,- 100 \\
\hline & & Sig. (2-tailed) & ,226 &, 000 & ,398 & 060 & . & ,723 \\
\hline & & $\mathrm{N}$ & 15 & 15 & 15 & 15 & 15 & 15 \\
\hline & \multirow[t]{3}{*}{ CrescAdmPub } & Correlation Coefficient &, 329 & 007 & 4,479 &,- 214 &,- 100 & 1,000 \\
\hline & & Sig. (2-tailed) & ,232 & ,980 & ,071 & ,443 & ,723 & \\
\hline & & $\mathrm{N}$ & 15 & 15 & 15 & 15 & 15 & 15 \\
\hline
\end{tabular}

Fonte elaborada pelos autores.

Ampliando a análise é possível verificar que somente os setores da indústria e dos serviços possuem correlação positiva e significativa a $1 \%$ com relação ao crescimento do PIB. O maior destaque é o setor de serviços com coeficiente de 0,921 (muito forte) seguido pelo setor industrial cujo coeficiente é de 0,671 (moderado). No entanto, a dinâmica das exportações não apresenta relação com esses dois setores mais preponderantes no crescimento econômico municipal, visto que não há relação significativa entre essas variáveis no período analisado, bem como a pauta de exportação tem participação ínfima do setor industrial.

Para ampliar esta análise por setores foi utilizada a regressão linear múltipla a fim de verificar a relação entre o Crescimento do PIB e as demais variáveis utilizadas, sendo o Crescimento do PIB utilizado como variável dependente e como variáveis independentes foram utilizadas as demais variáveis de crescimento. Foi utilizado o modelo hierárquico, onde as variáveis independentes são inseridas uma de cada vez no modelo, o que permite verificar a importância de cada variável em prever a variável de saída. Optou-se por iniciar a análise pelas variáveis com maior correlação com a variável dependente. A Figura 6 apresenta a sumarização do modelo. Pode-se observar que a inserção das variáveis Crescimento Agropecuário e Crescimento da Administração Pública não alteram de forma significativa o valor de $\mathrm{R}^{2}$ (Figura 5). 
Figura 5. Sumarização do Modelo ${ }^{\mathrm{e}}$

\begin{tabular}{|c|c|c|c|c|c|c|c|c|c|}
\hline \multirow[b]{2}{*}{ Modelo } & \multirow[b]{2}{*}{$\mathrm{R}$} & \multirow[b]{2}{*}{ R quadrado } & \multirow[b]{2}{*}{$\begin{array}{l}\mathrm{R} \text { quadrado } \\
\text { ajustado }\end{array}$} & \multirow[b]{2}{*}{$\begin{array}{l}\text { Erro padrão } \\
\text { da estimativa }\end{array}$} & \multicolumn{5}{|c|}{ Estatísticas de mudança } \\
\hline & & & & & $\begin{array}{l}\text { Mudança de } \\
\text { R quadrado }\end{array}$ & Mudança F & gl1 & gl2 & $\begin{array}{c}\text { Sig. Mudança } \\
\text { F }\end{array}$ \\
\hline 1 & $904^{\mathrm{a}}$ & 816 & 802 & 4,60626 & 816 & 57,826 & 1 & 13 & ,000 \\
\hline 2 &, $988^{\mathrm{b}}$ &, 977 &, 973 & 1,69603 & 161 & 83,890 & 1 & 12 &, 000 \\
\hline 3 & $990^{\circ}$ &, 979 &, 974 & 1,68053 &, 002 & 1,222 & 1 & 11 &, 292 \\
\hline 4 & $990^{\mathrm{d}}$ & ,980 & 973 & 1,71250 & ,001 &, 593 & 1 & 10 & .459 \\
\hline \multicolumn{10}{|c|}{ a. Preditores: (Constante), CRESCSERV } \\
\hline \multicolumn{10}{|c|}{ b. Preditores: (Constante), CRESCSERV, CRESCIND } \\
\hline \multicolumn{10}{|c|}{ c. Preditores: (Constante), CRESCSERV, CRESCIND, CRESCAGROP } \\
\hline \multicolumn{10}{|c|}{ d. Preditores: (Constante), CRESCSERV, CRESCIND, CRESCAGROP, CRESCADMPUBL } \\
\hline \multicolumn{10}{|c|}{ e. Variável Dependente: CRESCPIB } \\
\hline
\end{tabular}

Fonte: elaborada pelos autores.

A ANOVA do modelo de regressão múltipla permite verificar se as variáveis independentes conseguem prever o Crescimento do PIB, conforme pode-se observar na fFigura 6. Assim, observa-se que para todos os quatro modelos os valores de F são significativos. Assim, como o valor-p para o teste $\mathrm{F}$ de teste de significância global é menor que o nível de significância, pode-se rejeitar a hipótese nula e concluir que o modelo proporciona um ajuste melhor do que o modelo somente com o intercepto.

Figura 6. Anova ${ }^{a}$

\begin{tabular}{|c|c|c|c|c|c|c|}
\hline \multicolumn{2}{|c|}{ Modelo } & $\begin{array}{l}\text { Soma dos } \\
\text { Quadrados }\end{array}$ & gl & $\begin{array}{l}\text { Quadrado } \\
\text { Médio }\end{array}$ & $\mathrm{F}$ & Sig. \\
\hline \multirow[t]{3}{*}{1} & Regressão & 1226,938 & 1 & 1226,938 & 57,826 &, $000^{\mathrm{b}}$ \\
\hline & Resíduo & 275,829 & 13 & 21,218 & & \\
\hline & Total & 1502,767 & 14 & & & \\
\hline \multirow[t]{3}{*}{2} & Regressão & 1468,249 & 2 & 734,124 & 255,212 &, $000^{\circ}$ \\
\hline & Resíduo & 34,518 & 12 & 2,877 & & \\
\hline & Total & 1502,767 & 14 & & & \\
\hline \multirow[t]{3}{*}{3} & Regressão & 1471,701 & 3 & 490,567 & 173,703 &, $000^{\mathrm{d}}$ \\
\hline & Resíduo & 31,066 & 11 & 2,824 & & \\
\hline & Total & 1502,767 & 14 & & & \\
\hline \multirow[t]{3}{*}{4} & Regressão & 1473,440 & 4 & 368,360 & 125,606 & $.000^{\mathrm{e}}$ \\
\hline & Resíduo & 29,327 & 10 & 2,933 & & \\
\hline & Total & 1502,767 & 14 & & & \\
\hline \multicolumn{7}{|c|}{ a. Variável Dependente: CRESCPIB } \\
\hline \multicolumn{7}{|c|}{ b. Preditores: (Constante), CRESCSERV } \\
\hline \multicolumn{7}{|c|}{ c. Preditores: (Constante), CRESCSERV, CRESCIND } \\
\hline \multicolumn{7}{|c|}{ d. Preditores: (Constante), CRESCSERV, CRESCIND, CRESCAGROP } \\
\hline \multicolumn{7}{|c|}{ e. Preditores: (Constante), CRESCSERV, CRESCIND, CRESCAGROP, CRESCADMPUBL } \\
\hline
\end{tabular}

Fonte: elaborada pelos autores.

A figura 7, a seguir, apresenta, por meio da estatística t, quais coeficientes são significativos para o modelo. Confirma-se, mais uma vez, que apenas as variáveis Crescimento de 
Serviços e Crescimento Industrial são relevantes para o modelo. O mesmo quadro apresenta também os resultados do teste de colinearidade.

De acordo com Hair Jr. et al. (2009) a multicolinearidade pode ter efeitos consideráveis sobre a habilidade preditiva do modelo de regressão e sobre a estimação dos coeficientes de regressão e seus testes de significância estatística. Portanto, é importante avaliá-la nos modelos de regressão linear. Os autores salientam que uma maneira simples de identificar colinearidade é um exame da matriz de correlação para as variáveis independentes e, também, chamam atenção para o fato de tal medida ser uma indicação, apresentando duas medidas para avaliar a multicolinearidade.

A primeira medida é a tolerância. Deve-se observar que os valores de tolerância estão bem próximos de 1 (deve-se observar que em uma regressão linear simples uma variável independente teria tolerância 1, haja vista que é a única variável do modelo, não sendo afetada por outras). Outra medida é o fator de inflação de variância (VIF), que é o inverso do valor de tolerância, portanto valores próximos a 1 são desejáveis. Portanto, pode-se observar que o modelo não apresenta problemas de multicolinearidade.

Fica evidente pela análise da figura 7 que o setor que contribuiu com maior peso para tal crescimento é o de Serviços, seguido pela Indústria e pela Administração Pública e, por fim, pelo setor da Agropecuária. É notório a baixa contribuição do setor Agropecuária evidenciando a baixa relação de tal setor com o crescimento econômico da cidade, como já apontado pelas análises anteriores.

Figura 7. Teste da estatística t e de multicolinearidade.

\begin{tabular}{|c|c|c|c|c|c|c|c|c|c|c|c|c|c|}
\hline & & \multicolumn{2}{|c|}{ Coeficientes não padronizados } & \multirow{2}{*}{$\begin{array}{c}\begin{array}{c}\text { Coeficientes } \\
\text { padronizados }\end{array} \\
\text { Beta }\end{array}$} & \multirow[b]{2}{*}{$t$} & \multirow[b]{2}{*}{ Sig. } & \multicolumn{2}{|c|}{$\begin{array}{l}\text { 95,0\% Intervalo de Confiança } \\
\text { para B }\end{array}$} & \multicolumn{3}{|c|}{ Correlaçőes } & \multicolumn{2}{|c|}{ Estatisticas de colinearidade } \\
\hline \multicolumn{2}{|c|}{ Modelo } & B & Erro Padrão & & & & Limite inferior & $\begin{array}{l}\text { Limite } \\
\text { superior }\end{array}$ & Ordem zero & Parcial & Parte & Tolerância & VIF \\
\hline \multirow[t]{2}{*}{1} & (Constante) & 2,277 & 1,790 & & 1,272 & .226 & $-1,590$ & 6,145 & & & & & \\
\hline & CRESCSERV &, 788 &, 104 & .904 & 7,604 & .000 & .564 & 1,012 & .904 & .904 & .904 & 1,000 & 1,000 \\
\hline \multirow[t]{3}{*}{2} & (Constante) & 811 &, 678 & & 1,196 &, 255 & -.666 & 2,289 & & & & & \\
\hline & CRESCSERV & .645 & ,041 & ,739 & 15,625 &, 000 &, 555 &, 735 &, 904 & 976 & .684 &, 856 & 1,169 \\
\hline & CRESCIND & .292 &, 032 &, 433 & 9,159 &, 000 &, 222 &, 361 &, 714 & ,935 & , 401 &, 856 & 1,169 \\
\hline \multirow[t]{4}{*}{3} & (Constante) & .456 &, 745 & & 612 & .553 & $-1,184$ & 2,096 & & & & & \\
\hline & CRESCSERV & .668 & .046 &, 765 & 14,584 & .000 & 567 &, 768 & .904 & .975 & .632 & .683 & 1,464 \\
\hline & CRESCIND & .278 &, 034 & .413 & 8,232 &, 000 & .204 &, 353 & .714 & 928 &, 357 &, 746 & 1,341 \\
\hline & CRESCAGROP &, 012 &, 011 &, 055 & 1,106 & .292 &,- 012 &, 037 & -129 &, 316 & .048 & .771 & 1,297 \\
\hline \multirow[t]{5}{*}{4} & (Constante) &,- 666 & 1,642 & & -405 & 694 & $-4,325$ & 2,994 & & & & & \\
\hline & CRESCSERV & .662 & .047 & ,759 & 14,048 &, 000 &, 557 &, 767 &, 904 & 976 & ,621 & .668 & 1,496 \\
\hline & CRESCIND & .280 & ,035 & . 416 & 8,114 & ,000 & 203 &, 357 &, 714 & 932 & ,358 &, 741 & 1,349 \\
\hline & CRESCAGROP &, 009 & .012 & ,040 &, 743 & .475 & -018 & ,036 & -129 & .229 & ,033 &, 675 & 1,482 \\
\hline & CRESCADMPUBL & 109 &, 142 & , 036 &, 770 & .459 & -207 & .425 & .071 &, 237 & ,034 & .872 & 1,147 \\
\hline
\end{tabular}

Fonte: elaborada pelos autores. 
Destarte, partindo das análises realizadas e com os resultados apresentados confirma-se a hipótese geral HO de que a evolução das exportações de Varginha no período analisado não contribuiu significativamente para as taxas de crescimento econômico do município, especialmente por depender do setor agropecuário que apresenta baixa relação com o crescimento econômico e altas volatilidades em suas taxas de crescimento. Também é possível confirmar a hipótese $\mathrm{H} 1$ visto que o crescimento do setor agropecuário não apresentou relação significativa com o crescimento do PIB municipal no período em análise.

Nesse âmbito é importante resgatar os resultados de estudos como de Galimberti e Caldart (2010), realizado com municípios componentes do Conselho Regional de Desenvolvimento (Corede) Serra, no Rio Grande do Sul, referente ao período de 1997 a 2004, e de Carmo, Raiher e Stege (2017). O modelo apresentado na Figura 8 integra a noção de dinamicidade do ambiente exportador, conforme a noção de North (1955), e da complexidade dos produtos exportáveis, seguindo o entendimento de Gala (2017).

Figura 8 - Modelo explicativo da influência das exportações no crescimento de setores e do PIB municipal

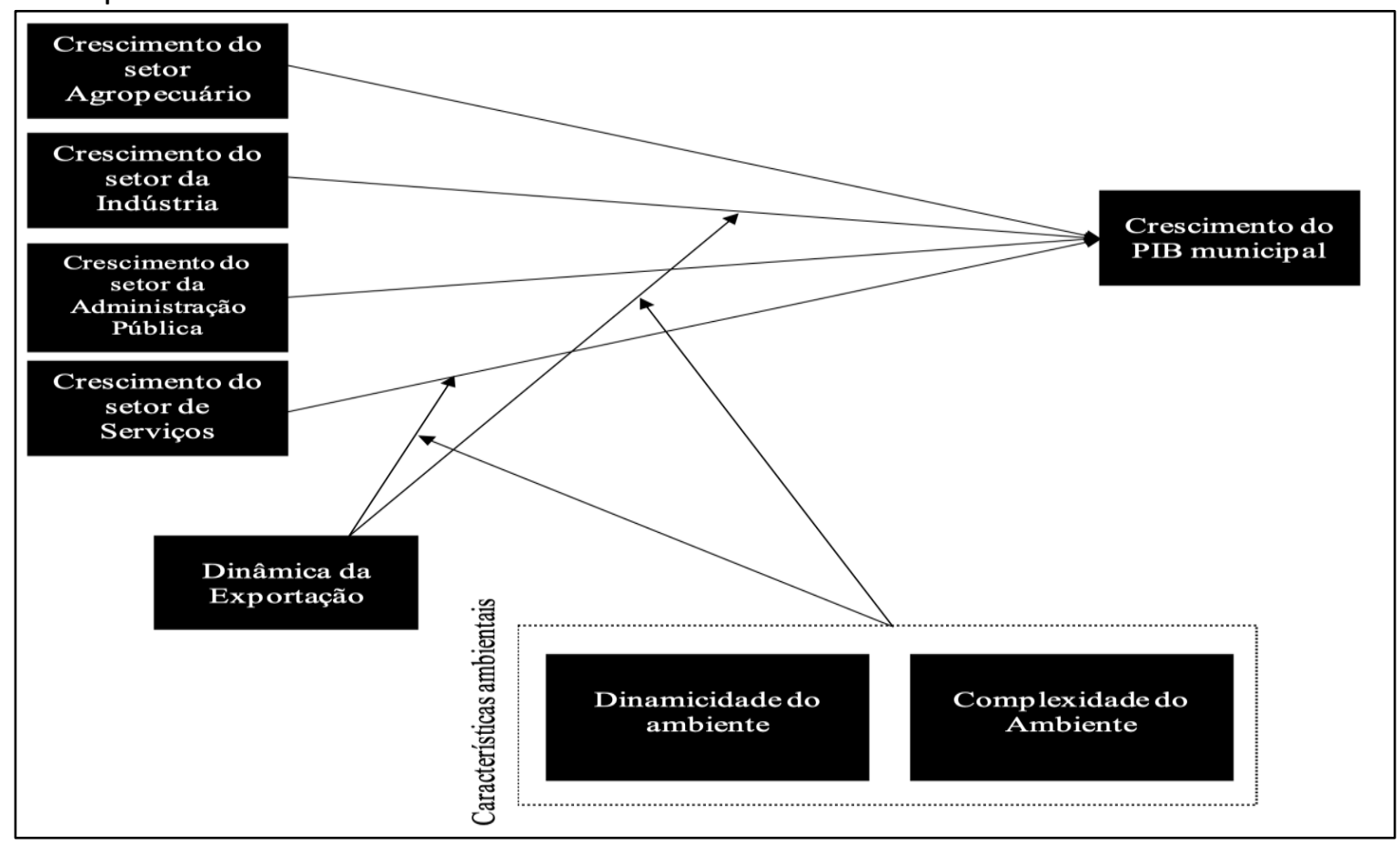

Fonte: elaborada pelos autores, a partir de North (1955) e de Gala (2017).

Estudos aplicando o modelo de Feder (1983) concluíram que a promoção das exportações permite impulsionar o crescimento econômico no âmbito municipal e de maneira indireta nas microrregiões brasileiras. No entanto, isso somente se torna possível quando as empresas 
exportadoras detenham maiores níveis de produtividade e sejam mais intensivas em tecnologia, o que ocorre essencialmente em setores mais dinâmicos e complexos como a indústria, em detrimento dos setores puramente dependentes de commodities (CRESPO-CUARESMA, WÖRZ, 2003; GALA, 2017).

Assim, para que a dinâmica das exportações possa contribuir para o crescimento econômico municipal é necessário que se relacione com os setores de serviços e indústria, produzindo bens e serviços complexos que permitem uma inserção mais profunda no mercado internacional, e que tal inserção não seja estática, mas sim dinâmica, o que significa a constante inovação e surgimento de novos produtos.

\section{Considerações finais}

O presente estudo teve por objetivo realizar uma análise sobre o comportamento das exportações em Varginha - MG e como isso influenciou nas taxas de crescimento econômico do município, tendo como base a Teoria da Base de Exportação desenvolvida por Douglas North.

Observou-se que as exportações do município de Varginha não contribuíram para o seu crescimento econômico devido à estática da pauta de exportação na maior parte do período observado, no qual os produtos de origem agropecuária foram responsáveis pela quase totalidade do que foi exportado. A ausência de uma dinâmica na base exportadora inibe que esse componente da demanda agregada contribua de forma efetiva para o crescimento econômico mais sustentável do município.

O estudo ainda permitiu verificar que o comportamento do setor agropecuário não possui relação significativa com o crescimento econômico e nem mesmo com as variações dos demais setores, o que corrobora com os resultados da análise da pauta de exportação.

Importante salientar que o intuito do estudo não é condenar a pauta de exportação agrícola varginhense, mas levantar discussões e críticas, demonstrando que o município poderia apresentar melhores e mais estáveis resultados em seu crescimento econômico se desenvolvesse uma base de exportação mais dinâmica e diversificada, talvez com ênfase na produção industrial, cujo setor contribui de forma mais significativa para o crescimento econômico. O investimento no processo de industrializar o produto base do município, o café, poderia ser uma alternativa a ser considerada nesse aspecto, o que permitiria agregar valor ao produto final e não abandonar a vocação do local. 
Como limitações desse trabalho salientam-se o uso apenas da análise do coeficiente de correlação dos dados levantados e a abordagem apenas no período de 2003 a 2017 para as taxas de crescimento de PIB, exportações e setores econômicos, e de 2009 a 2017 para a pauta de exportação, visto serem esses os períodos com dados disponíveis.

Para futuros estudos recomenda-se a aplicação de ferramentas estatísticas mais avançadas para análise dos dados e verificar os índices de encadeamento da agropecuária do município com as demais atividades econômicas.

\section{Referências}

ABEL, A. B.; BERNANKE, B. S.; CROUSHORE, D. Macroeconomia. 6. ed. São Paulo: Pearson Prentice Hall, 2008.

BENKO, G. A ciência regional. Oeiras: Celta, 1999.

BISQUERA, R.; SARRIERA, J. C.; MARTINEZ, F. Introdução à Estatística: enfoque informático com o pacote estatístico SPSS. 1. ed. Porto Alegre: Artmed, 2004.

BOUDEVILLE, J.-R. Les spaces économiques. Paris: Press Universitaires de France, 1970.

CARMO, A. S. S.; RAIHER, A. P.; STEGE, A. L. O efeito das exportações no crescimento econômico das microrregiões brasileiras: uma análise espacial com dados em painel. Estudos Econômicos, v. 7, n. 1, p. 153-183, jan.-mar. 2017.

CRESPO-CUARESMA, J.; WÖRZ, J. On export composition and growth. Viena: University of Vienna, Department of Economics, 2003.

CONOVER, W. J. Practical nonparametric statistics. 3. ed. New York: John Wiley \& Sons, 1999.

DALBERTO, C. R.; CIRINO, J. F.; STADUTO, J. A. R. Especialização versus diversificação:

economias de aglomeração e seus impactos sobre os salários industriais em Minas Gerais.

Gestão \& Regionalidade, v. 32, n. 95, p. 143-159, maio-ago. 2016. doi:

$10.13037 /$ gr.vol32n95.3268

EMATER. Empresa de Assistência Técnica e Extensão Rural do Estado de Minas Gerais.

Conhecendo a cafeicultura de Minas Gerais. Belo Horizonte: MG. Disponível em < http://www.emater.mg.gov.br/portal.do/site-noticias/conhecendo-a-cafeicultura-de-minasgerais/?flagweb=novosite_pagina_interna\&id=22530>. Acesso em 06 de maio de 2019.

FEDER, G. On exports and economic growth. Journal of Development Economics, v. 12, p. 5973, 1983.

FIELD, A. Descobrindo a estatística usando o SPSS. 2. ed. Porto Alegre: Artmed, 2009.

FIGUEIREDO FILHO, D. B.; SILVA JUNIOR, J. A. Desvendando os Mistérios do Coeficiente de Correlação de Pearson (r). Revista Política Hoje, v. 18, n. 1, 2010.

FINNEY, D. J. Statistics for biologists. Londres: Chapman and Hall, 1980.

FJP - FUNDAÇÃO JOÃO PINHEIRO. Produto Interno Bruto dos Municípios. 2020. Disponível em: http://novosite.fjp.mg.gov.br/produto-interno-bruto-pib-de-minas-gerais/ Acesso em: 03 mar. 2020.

FURTADO, C. Teoria e política do desenvolvimento econômico. 10. ed. Rio de Janeiro: Paz E 
Terra, 2000.

GALA, P. Complexidade econômica: uma nova perspectiva para entender a antiga questão da riqueza das nações. Rio de Janeiro: Contraponto: Centro Internacional Celso Furtado de Políticas para o Desenvolvimento, 2017.

GALIMBERTI, J.K.; CALDART, W.L. As exportações e o crescimento econômico: análise dos municípios do Corede Serra - 1997-04. Ensaios FEE, Porto Alegre, v. 31, n. 1, p. 87-112, ago. 2010

GIL, A. C. Métodos e técnicas de pesquisa social. 5. ed. São Paulo: Atlas, 2007.

HAIR Jr., J.F.; BLACK, W.C.; BABIN, B.J.; ANDERSON, R.E. \& TATHAM, R.L. Análise multivariada de dados. 6.ed. Porto Alegre, Bookman, 2009.

HIRSCHMAN, A. O. The strategy of economic development. New Haven: Yale University Press, 1958.

IBGE - Instituto Brasileiro de Geografia e Estatística. O recorte das regiões geográficas imediatas e intermediárias de 2017. 2017. Disponível em:

https://www.ibge.gov.br/apps/regioes_geograficas/ Acesso em: 05 mar. 2020.

Deflator do Produto Interno Bruto. 2019. Disponível em:

https://sidra.ibge.gov.br/tabela/6784 Acesso em: 10 mar. 2020.

IPEA - Instituto de Pesquisa Econômica Aplicada. Taxa de câmbio nominal. 2020. Disponível em:

http://www.ipeadata.gov.br/ExibeSerie.aspx?serid=31924\&module=M\&chart=Charts/mage404 $\underline{17902344583176}$ Acesso em 10 mar. 2020.

LIMA, A. C. C.; SIMÕES, R. F. Teorias do desenvolvimento regional e suas implicações de política econômica no pós - Guerra: o caso do Brasil. Texto para discussão 358. Belo Horizonte:

UFMG/CEDEPLAR, 2009. Disponível em:

http://www.cedeplar.ufmg.br/pesquisas/td/TD\%20358.pdf

LIMA, E. C.; LIMA, E. P. C.; EVAS, I. M.; TEIXEIRA, M. S. G. Teoria da base de exportação e sua relação com o desempenho econômico: o caso do estado de Santa Catarina. Textos de economia, Florianópolis, v. 16, n. 1, p. 95-116, jan.-jun. 2013.

MDIC - MINISTÉRIO DO DESENVOLVIMENTO, INDÚSTRIA E COMÉRCIO EXTERIOR. ISIC Classificação Internacional de Todas as Atividades Econômicas. 2020a. Disponível em: http://comexstat.mdic.gov.br/pt/comex-vis Acesso em 02 mar. 2020.

. Exportação e Importação Municípios. 2020b. Disponível em:

http://comexstat.mdic.gov.br/pt/municipio Acesso em 10 mar. 2020.

MYRDAL, G. Economic theory and under-developed regions. Gerald Duckworth \& CO. LTD: London, 1957

NORTH, D. Teoria de localização e crescimento econômico regional. 1955. In: SCHWARTZMAN, J. (Org.). Economia regional: textos selecionados. Belo Horizonte: CEDEPLAR, 1977.

. A agricultura no crescimento econômico regional. 1959. In: SCHWARTZMAN, J.

(Org.). Economia regional: textos selecionados. Belo Horizonte: CEDEPLAR, 1977.

NURKSE, R. Problemas da formação de capital em países subdesenvolvidos. Rio de Janeiro: Civilização Brasileira, 1957. 
ÖZTUNA, D.; ELHAN, A. H.; TÜCCAR, E. Investigation of four different normality tests in terms of type 1 error rate and power under different distributions. Turkish Journal of Medical Sciences, v. 36, n. 3, jun. 2006, p. 171-176. Disponível em: https://dergipark.org.tr/tr/download/articlefile/129239 Acesso em: 15 mar. 2020.

PERROUX, F. A Economia do século XX. Porto: Herder, 1967

. O conceito de polo de crescimento. In: SCHWARTZMAN, J. Economia regional:

textos escolhidos. Belo Horizonte: CEDEPLAR, 1977.

SCHUMPETER, J. A. Capitalismo, socialismo e democracia. Rio de Janeiro: Zahar, 1942.

SOUZA, N. J. Teoria dos polos, regiões inteligentes e sistemas regionais de inovação. Análise, v. 16, n. 1, jan./jul. 2005, p. 87 - 112. Disponível em:

http://revistaseletronicas.pucrs.br/ojs/index.php/face/article/view/266/215

THIRLWALL, A. P. Trade, trade liberalisation and economic growth: theory and evidence. Tunisia: African Development Bank, Cote d'Ivoire, 2000.

TIEBOUT, C. M. As exportações e o crescimento econômico regional. In: SCHWARTZMAN, J. (Org.). Economia regional: textos selecionados. Belo Horizonte: CEDEPLAR, 1977.

TORMAN, V. B. L.; COSTER, R.; RIBOLDI, J. Normalidade de variáveis: métodos de verificação e comparação de alguns testes não-paramétricos por simulação. Revista HCPA, v. 32, n. 2, 2012, p. 227-234. Disponível em: https://seer.ufrgs.br/hcpa/article/view/29874/19186 Acesso em: 05 mar. 2020.

VERGARA, S. C. Projetos e relatórios de pesquisa em administração. 6. ed. São Paulo: Atlas, 2005.

YIN, R. K. Estudo de Caso: Planejamento e métodos. São Paulo: Bookman, 2015. 